\title{
Numerical evaluation of pollutant dispersion in the built environment: comparisons between models and experiments
}

\author{
B. Blocken ${ }^{\mathrm{a},},{ }^{*}$ T. Stathopoulos ${ }^{\mathrm{b}}$, P. Saathoff ${ }^{\mathrm{b}}, \mathrm{X}$. Wang ${ }^{\mathrm{b}}$
}

\author{
(a) Building Physics and Systems, Technische Universiteit Eindhoven, P.O. box 513, 5600 MB Eindhoven, \\ the Netherlands \\ (b) Department of Building, Civil and Environmental Engineering, Concordia University, \\ 1455 de Maisonneuve Blvd West, H3G 1M8, Montreal, Quebec, Canada
}

\begin{abstract}
Steady-state RANS Computational Fluid Dynamics simulations of pollutant dispersion in the neutrally stable atmospheric boundary layer are made with the commercial code Fluent 6.1 for three case studies: plume dispersion from an isolated stack, low-momentum exhaust from a rooftop vent on an isolated cubic building model and high-momentum exhaust from a rooftop stack on a low-rise rectangular building with several rooftop structures. The results are compared with the Gaussian model, the semi-empirical ASHRAE model and wind tunnel and full-scale measurements. It is shown that in all three cases and with all turbulence models tested, the lateral plume spread is significantly underestimated. It is suggested that transient simulations might be required to achieve more accurate results. The numerical results are quite sensitive to the value of the turbulent Schmidt number. The comparisons however can not clearly indicate which Schmidt number is most suitable for which type of flow due to the large number of other error sources in the simulations, including steady-state RANS modelling, turbulence modelling, near-wall treatment limitations and unintended streamwise gradients in the turbulent kinetic energy profiles.
\end{abstract}

Keywords: Building; CFD; Design; Dispersion; Pollution; Plume; Roof; Vent; Stack; Turbulence model

\section{Introduction}

Air pollution can have a wide range of negative consequences for human health and productivity. Emissions from single-standing stacks, rooftop vents and stacks can affect indoor air quality if the plume impinges on air intakes of the emitting building or the surrounding buildings. The precise prediction of pollutant concentration distributions on or near buildings is very important for building engineers to design proper exhaust stacks and set proper air intakes to avoid adverse air quality impacts. The prediction of such concentrations is a difficult task, especially in the urban environment. It does not only require the knowledge of air pollution meteorology and dispersion, it also requires knowledge of building aerodynamics because wind and buildings can strongly affect plume behaviour.

A comprehensive review of air pollution aerodynamics was recently compiled by Meroney (2004), addressing the wide range of methods that exist for predicting pollutant dispersion, ranging from field tests and wind tunnel simulations to semi-empirical methods and numerical simulations with Computational Fluid Dynamics (CFD). Several field tests have been conducted in the past (Barad 1958, Wilson and Lamb 1994, Lazure et al. 2002, Stathopoulos et al. 2002, 2004). They are very valuable because they are conducted in the real atmospheric boundary layer and provide information on the real complexity of the phenomenon.

Disadvantages however are the uncontrollable nature and variation of wind and weather conditions. Moreover, it is impossible to measure resulting pollutant distributions if a new facility or a new building has not yet been constructed. As opposed to field tests, wind tunnel modelling allows controlled physical simulation of dispersion processes (Halitsky 1963, Huber and Snyder 1982, Li and Meroney 1983, Saathoff et al. 1995, 1998, Leitl et al. 1997, Meroney et al. 1999, Stathopoulos et al. 2002, 2004). Drawbacks of wind tunnel tests are that they can be time-consuming and costly, that they are not applicable for light wind conditions, and that scaling - similarity can be a difficult issue. Semi-empirical models, such as the Gaussian model (Turner 1970, Pasquill and Smith 1983) and the so-called ASHRAE models (Wilson and Lamb 1994, ASHRAE 1999, 2003) are relatively simple and easy-to-use, at the expense of limited applicability and less accurate estimates. The Gaussian model, in its original form, is not applicable when there are obstacles between the emission source and the receptor, and the ASHRAE models only evaluate the minimum dilution factor on the plume centreline. Numerical simulation with CFD offers some advantages compared to other methods: it is often said to be less expensive than field and wind

\footnotetext{
* Corresponding author: B. Blocken, Building Physics and Systems, Technische Universiteit Eindhoven, P.O. box 513, $5600 \mathrm{MB}$ Eindhoven, the Netherlands.

Tel.: +31 (0)40 247 2138, Fax +31 (0)40 243 8595, E-mail: b.j.e.blocken@tue.nl
} 
tunnel tests and it provides results of the flow features at every point in space simultaneously. However, CFD requires specific care in order for the results to be reliable. Important parameters determining the accuracy of CFD simulations are the grid resolution and iterative convergence ( $\mathrm{Li}$ and Stathopoulos 1998), the choice of turbulence models and near-wall treatment (Franke et al. 2007), avoiding unintended streamwise gradients in the approach flow profiles of mean wind speed and turbulence quantities (Blocken et al. 2007a, 2007b), the order of the discretisation schemes, etc. CFD simulations of turbulent flow based on the Reynolds-averaged NavierStokes (RANS) equations or with LES should at least always be validated by comparison with high-accuracy experimental data. CFD simulations of pollutant dispersion are further complicated by the fact that the knowledge of the turbulent Schmidt $\mathrm{Sc}_{t}$ is required prior to the simulation. It is defined as the ratio of momentum diffusivity $v_{t}$ to mass diffusivity $D_{t}$, and describes the relative diffusion of momentum and mass due to turbulence. The lack of knowledge about this number has lead to the use of the inverse procedure in CFD, i.e. determining the Schmidt number not a priori, but after a series of CFD simulations with different $\mathrm{Sc}_{\mathrm{t}}$ numbers and after model validation of each of these simulations to determine the most appropriate one.

In the past decade, several CFD simulations of pollutant dispersion were performed, for different building and stack configurations. Riddle et al. (2004) simulated dispersion of emissions from a $30 \mathrm{~m}$ high isolated stack under neutral open country conditions using Fluent 6.1 with $\mathrm{Sc}_{\mathrm{t}}=0.3$. Tang et al. (2005) used Fluent 6.2 to simulate plume dispersion from a ground level source in an open field. Compared with field data, the numerical results performed well for concentration distribution along the plume centreline and in the lateral direction. The best agreement was obtained with $\mathrm{Sc}_{\mathrm{t}}=1.0$ for distances further than $50 \mathrm{~m}$ from the stack and with $\mathrm{Sc}_{\mathrm{t}}=1.3$ for distances equal to $50 \mathrm{~m}$ from the stack. $\mathrm{Li}$ and Stathopoulos (1997) evaluated pollutant distribution around a rectangular building model with the $\mathrm{k}-\varepsilon$ model and $\mathrm{Sc}_{\mathrm{t}}=0.7$. Numerical results agreed well with experimental data for positions far downwind of the building, but agreed less satisfactorily for positions close to the wall and within the wake zone. Meroney et al. (1999) found the Reynolds Stress model (RSM) to produce more realistic airflow fields around buildings than the standard or RNG k- $\varepsilon$ models compared with wind tunnel test results. Concentrations on the leeward wall however were overestimated by more than one order of magnitude. The authors however stated that they intentionally did not make any attempt to tune the model to obtain a better correspondence. Banks et al. (2003) simulated dispersion of exhaust from a short stack on a rectangular building roof using the standard $\mathrm{k}-\varepsilon$ model. Comparing longitudinal concentration profiles along the plume centreline with experimental data and the US EPA SCREEN 3 model, they found CFD calculations overestimated by 5 to 10 times the peak concentration downstream of the stack on the roof for all cases. The numerical predictions of the downstream ground level concentrations however were quite accurate.

This paper presents CFD simulations of pollutant dispersion for three case studies with increasing complexity: plume dispersion from an isolated stack, low-momentum exhaust from a rooftop vent on an isolated cubic building model and high-momentum exhaust from a rooftop stack on a low-rise rectangular building with several rooftop structures. Some earlier work on this project was carried out by Wang (2006) and Wang et al. (2006). In each simulation in this paper, the exhaust is considered to be passive and thermal effects are absent. Several turbulence models, near-wall treatments and $\mathrm{Sc}_{\mathrm{t}}$ numbers are employed and the numerical results are compared with semi-empirical models and experimental data.

\section{Governing equations and turbulence models}

The governing equations are the steady-state Reynolds-averaged Navier-Stokes (RANS) equations supplemented with the Eulerian diffusion-advection equation (Eq. 1):

$\mathrm{U}_{\mathrm{j}} \frac{\partial \mathrm{C}}{\partial \mathrm{x}_{\mathrm{j}}}=\mathrm{D}_{\mathrm{t}} \frac{\partial^{2} \mathrm{C}}{\partial \mathrm{x}_{\mathrm{j}} \partial \mathrm{x}_{\mathrm{j}}}$

where $i, j=1,2,3$, $U$ is the mean velocity, $C$ is the mean mass fraction of the pollutant and $D_{t}$ the turbulent mass diffusivity $\left(=v_{t} / S_{t}\right)$. The default $S_{c}$ in Fluent 6.1 is 0.7 .

Several turbulence models are used in this study, including the standard k- $\varepsilon$ model (Jones and Launder 1972), the realizable k- $\varepsilon$ model (Shih et al. 1995) and the Reynolds Stress model (RSM) (Launder et al. 1975) with a linear pressure-strain model and wall-reflection effects (Gibson and Launder 1978, Launder 1989). The wallreflection term ensures redistribution of the normal stresses near the wall. It tends to damp the normal stress perpendicular to the wall while enhancing the stresses parallel to the wall. The turbulence model equations can be found in the related references, the model constants used in this study are:

- standard k- $\varepsilon$ model: $\mathrm{C}_{1 \varepsilon}=1.44 ; \mathrm{C}_{2 \varepsilon}=1.92 ; \mathrm{C}_{\mu}=0.09 ; \sigma_{\mathrm{k}}=1.0 ; \sigma_{\varepsilon}=1.3$

- realizable k- $\varepsilon$ model: $\mathrm{C}_{2}=1.9 ; \sigma_{\mathrm{k}}=1.0 ; \sigma_{\varepsilon}=1.2$ 
- $\quad$ RSM with wall reflection effects: $\mathrm{C}_{1 \varepsilon}=1.44 ; \mathrm{C}_{2 \varepsilon}=1.92 ; \mathrm{C}_{\mu}=0.09 ; \mathrm{C}_{1 \mathrm{PS}}=1.8 ; \mathrm{C}_{2 \mathrm{PS}}=0.6 ; \mathrm{C}_{1}{ }^{\prime}{ }_{\mathrm{PS}}=0.5$; $\mathrm{C}_{2}{ }^{\prime} \mathrm{PS}=0.3 ; \sigma_{\mathrm{k}}=1.0 ; \sigma_{\varepsilon}=1.3$

In the subscripts, PS refers to "pressure-strain". Note that these constants apply for the high-Reynolds number RSM which is used in combination with wall functions. When low-Reynolds number modelling is required, the constants for the wall-reflection term are modified as functions of the Reynolds stress invariants and the turbulent Reynolds number (Launder and Shima 1989).

\section{Results}

\subsection{Dispersion of exhaust from an isolated stack}

Plume dispersion from an isolated stack is calculated under neutral open country conditions for two stack heights: $\mathrm{h}_{\mathrm{S}}=2 \mathrm{~m}$ and $16 \mathrm{~m}$ with an inner diameter of $0.2 \mathrm{~m}$ and $0.6 \mathrm{~m}$ respectively. The 3D computational domain has dimensions $\mathrm{L} \times \mathrm{B} \times \mathrm{H}=1050 \times 350 \times 100 \mathrm{~m}^{3}$ for both stacks. The $2 \mathrm{~m}$ and $16 \mathrm{~m}$ stack are located at $14 \mathrm{~m}$ and $42 \mathrm{~m}$ from the domain inlet, respectively. Two coordinate systems are defined: $(\mathrm{x}, \mathrm{y}, \mathrm{z})$ with the origin at the inlet of the domain, and ( $\left.\mathrm{x}^{\prime}, \mathrm{y}^{\prime}, \mathrm{z}^{\prime}\right)$ with the origin at the stack location (see Fig. 1b). $\mathrm{x}, \mathrm{y}$ and $\mathrm{z}$ respectively indicate the streamwise, lateral and vertical position. The grid resolution is based on grid-sensitivity analysis, yielding grids of about $4.9 \times 10^{5}$ and $3.2 \times 10^{5}$ prismatic cells respectively. The distance $\mathrm{z}_{\mathrm{P}}$ of the centre point $\mathrm{P}$ of the wall-adjacent cells to the ground surface (bottom of domain) is $0.06 \mathrm{~m}$ for the $2 \mathrm{~m}$ stack and $0.3 \mathrm{~m}$ for the 16 $\mathrm{m}$ stack. The inlet profile of mean wind speed is a power law with exponent $\alpha=0.15$ with $U=2.2 \mathrm{~m} / \mathrm{s}$ at $2 \mathrm{~m}$ height and $3 \mathrm{~m} / \mathrm{s}$ at $16 \mathrm{~m}$ height (Fig. 1a). The turbulent kinetic energy profile is calculated from turbulence intensity measurements in a wind tunnel (Stathopoulos and Storms 1986). The turbulence dissipation rate profile is $\varepsilon=\mathrm{u}^{* 3} / \mathrm{Kz}$ where $\mathrm{\kappa}$ is the von Karman constant $(0.42)$ and $\mathrm{u}^{*}$ is the friction velocity $(0.22 \mathrm{~m} / \mathrm{s})$, for an aerodynamic roughness length $z_{0}=0.03 \mathrm{~m}$. The standard wall functions by Launder and Spalding (1974) with sand-grain based roughness modification (Cebeci and Bradshaw 1977) are used at the bottom of the computational domain. These wall functions require the equivalent sand-grain roughness height $\mathrm{k}_{\mathrm{S}, \mathrm{ABL}}$ for the atmospheric boundary layer as input, which can, for Fluent 6.1 , be determined from $\mathrm{z}_{0}$ and $\mathrm{C}_{\mathrm{S}}$ based on the equation $\mathrm{k}_{\mathrm{S}, \mathrm{ABL}}=9.793 \mathrm{z}_{0} / \mathrm{C}_{\mathrm{S}}$ - see more details on this matter in (Blocken et al. 2007a). With the default roughness constant $C_{\mathrm{S}}=0.5, \mathrm{k}_{\mathrm{S}, \mathrm{ABL}}$ should be $0.59 \mathrm{~m}$. However, because Fluent 6.1 does not allow the value of $\mathrm{k}_{\mathrm{S}}$ to be larger than $\mathrm{z}_{\mathrm{P}}, \mathrm{k}_{\mathrm{S}}$ will be limited to $0.06 \mathrm{~m}$ for the $2 \mathrm{~m}$ stack and $0.3 \mathrm{~m}$ for the $16 \mathrm{~m}$ stack. Because the correct roughness height cannot be used, streamwise changes will occur in the vertical profiles of the mean wind speed and turbulence quantities as they travel through the computational domain (Blocken et al. 2007a,b). To assess the extent of these changes, 3D simulations were made in two empty computational domains, with grid distributions similar to the two domains with the stack models. Fig. 1a and Fig. 2a show the profile changes by plotting the profiles at three positions: $\mathrm{x}=0 \mathrm{~m}$ (inlet plane), $\mathrm{x}^{\prime}=100 \mathrm{~m}$ (100 $\mathrm{m}$ downstream of the stack), and $\mathrm{x}^{\prime}$ $=1000 \mathrm{~m}$. Streamwise gradients are most pronounced for the turbulent kinetic energy profile. The sides of the domain are modelled as slip walls (zero normal velocity and zero normal gradients of all variables). At the top of the domain, fixed values for $\mathrm{U}, \mathrm{k}$ and $\varepsilon$ are applied corresponding to the values of the inlet profiles at this height (Blocken et al. 2007a). At the outlet, zero static pressure is set. The computations simulated the release of a tracer gas from the top of the stack. The momentum ratio $\mathrm{M}=\mathrm{W}_{\mathrm{e}} / \mathrm{U}_{\mathrm{S}}$, where $\mathrm{W}_{\mathrm{e}}$ is the vertical exhaust speed and $\mathrm{U}_{\mathrm{S}}$ the horizontal wind speed at stack height, was 4 for the $2 \mathrm{~m}$ stack and 2 for the $16 \mathrm{~m}$ stack.

The RANS equations are solved using Fluent 6.1. The standard k- $\varepsilon$ turbulence model is used to provide closure. Pressure-velocity coupling is taken care of by the SIMPLEC algorithm. Pressure interpolation is second order. Second-order discretisation schemes are used for both the convection terms and the viscous terms of the governing equations.

The CFD concentration distributions are compared with predictions by the so-called Gaussian dispersion model for sources releasing continuously under steady-state conditions. Considering ground reflection, the Gaussian dispersion equation is given as (Turner, 1970):

$$
\frac{\chi(\mathrm{x}, \mathrm{y}, \mathrm{z}, \mathrm{H}) U_{p}}{q}=\frac{\exp \left(-\mathrm{y}^{2} / 2 \sigma_{\mathrm{y}}^{2}\right)}{2 \pi \sigma_{\mathrm{y}} \sigma_{z}}\left[\exp \left(-\frac{\left(H_{p}-z\right)^{2}}{2 \sigma_{z}^{2}}\right)+\exp \left(-\frac{\left(H_{p}+z\right)^{2}}{2 \sigma_{z}^{2}}\right)\right]
$$

where $\chi$ is the air pollutant concentration $\left(\mathrm{g} / \mathrm{m}^{3}\right), \mathrm{U}_{\mathrm{p}}$ the mean wind speed affecting the plume $(\mathrm{m} / \mathrm{s}), \mathrm{q}$ the pollutant emission rate $(\mathrm{g} / \mathrm{s}), \mathrm{H}_{\mathrm{p}}$ the effective height of the centreline of the plume and the dispersion parameters $\sigma_{\mathrm{y}}$ and $\sigma_{\mathrm{z}}(\mathrm{m})$ are the standard deviations of the concentration distribution in the lateral and vertical direction respectively. Both dispersion parameters are a function of downstream distance $\mathrm{x}$. In this study, the parameters 
for neutral conditions (class D) are taken from Turner (1970). The effective plume height $\mathrm{H}_{\mathrm{p}}$ is defined as $\mathrm{H}_{\mathrm{p}}=$ $\mathrm{H}_{\mathrm{S}}+\mathrm{h}_{\mathrm{r}}-\mathrm{h}_{\mathrm{d}}$ where $\mathrm{H}_{\mathrm{S}}$ is the stack height, $\mathrm{h}_{\mathrm{r}}$ the plume rise and $\mathrm{h}_{\mathrm{d}}$ the stack wake downwash. For momentum ratios $\mathrm{M}>1.5, \mathrm{~h}_{\mathrm{d}}=0$. The maximum plume rise due to exhaust momentum for a bent-over jet under Pasquill's neutral stability is $\Delta \mathrm{h}_{\max }=3 \mathrm{dM}$ (Briggs 1994) with $\mathrm{d}$ the inner stack diameter. Since the plume rise from a stack occurs over some distance downwind, Eq. (2) should not be applied within the first hundred meter from the stack. Note that the wind speed $\mathrm{U}_{\mathrm{p}}$ at height $\mathrm{H}_{\mathrm{p}}$ has been used in this paper to evaluate Eq. (2). According to Turner (1970), the Gaussian model should be able to predict concentration distributions within a factor of 3.

The CFD results and the results by the Gaussian model for the $2 \mathrm{~m}$ stack are compared in Fig. 1b-d. Fig. 1b illustrates the ground-level downstream concentration distribution (along the $\mathrm{x}$ '-axis) obtained with different $\mathrm{Sc}_{\mathrm{t}}$ compared to the Gaussian prediction. At every location along this axis, the numerical discretisation error $\varepsilon_{\mathrm{d}}$ is below $8 \%$. The correspondence with the Gaussian model is best for $\mathrm{Sc}_{\mathrm{t}}=0.3$, for which an acceptable agreement is obtained. Fig. 1c illustrates ground-level lateral (cross-wind) concentration distributions at different downstream distances $\left(\mathrm{x}^{\prime}=100,200\right.$ and $500 \mathrm{~m}$ ) for $\mathrm{Sc}_{\mathrm{t}}=0.3 . \varepsilon_{\mathrm{d}}$ remains below $50 \%$ for at least $\mathrm{XU}_{\mathrm{p}} / \mathrm{q}^{>} 10^{-6} \mathrm{~m}^{-}$ ${ }^{2}$. As the downwind distance increases, the deviations of the CFD results from the Gaussian prediction become very large. Clearly, the prediction of lateral plume spread by the simulations is very poor. Vertical concentration profiles along lines at different downwind distances and for $\mathrm{y}^{\prime}=0 \mathrm{~m}$ are given in Fig. $1 \mathrm{~d}$. For these results, $\varepsilon_{\mathrm{d}}$ remains below $5 \%$ for at least $\mathrm{z}<15 \mathrm{~m}$. The overestimations are at least partly due to the poor prediction of lateral plume spread. Similar conclusions concerning the difference between the numerical results and the Gaussian model are drawn from the $16 \mathrm{~m}$ stack results. In Fig. $2 \mathrm{~b}, \varepsilon_{\mathrm{d}}$ is below $11 \%$ for $\mathrm{x}>180 \mathrm{~m}$. For the results in Fig. $2 \mathrm{c}, \varepsilon_{\mathrm{d}}$ is large, but remains below $90 \%$ for at least $\mathrm{XU}_{\mathrm{p}} / \mathrm{q}>10^{-9} \mathrm{~m}^{-2}$. For the results in Fig. $2 \mathrm{~d}$, $\varepsilon_{\mathrm{d}}$ remains below $10 \%$ at plume height $\left(\mathrm{H}_{\mathrm{p}} \approx 20 \mathrm{~m}\right)$. Overall, $\varepsilon_{\mathrm{d}}$ increases below and above $\mathrm{z}=20 \mathrm{~m}$, but remains below $50 \%$ for at least $\mathrm{z}<30 \mathrm{~m}$. Note that although Fig. $2 \mathrm{~b}$ seems to indicate a better agreement with the Gaussian model results for $\mathrm{Sc}_{\mathrm{t}}=0.5$, overall, the best agreement was obtained for $\mathrm{Sc}_{\mathrm{t}}=0.3$.

\subsection{Dispersion from a rooftop vent on an isolated cubic building}

Numerical simulations are made to reproduce the experiments by Li and Meroney (1983), in which tracer gas was released from a rooftop vent on a $0.05 \mathrm{~m}$ cube in a wind tunnel with an exhaust momentum ratio $\mathrm{M}=0.07$. The simulations are conducted at model scale in a domain with dimensions $\mathrm{LxBxH}=1 \times 0.5 \times 0.5 \mathrm{~m}^{3}$. The cube is placed at $0.2 \mathrm{~m}$ from the inlet. Grid sensitivity analysis has led to a grid with $3.3 \times 10^{5}$ prismatic cells. Fig. $3 \mathrm{a}$ illustrates the grid on the building and ground surface. For the ground surface, the distance $\mathrm{z}_{\mathrm{P}}$ is $0.0013 \mathrm{~m}$. The inlet profile is a power law with exponent $\alpha=0.19$. Mean wind speed at roof height $U_{H}$ is $3.3 \mathrm{~m} / \mathrm{s}, \mathrm{z}_{0}$ is $7.5 \times 10^{-5}$ $\mathrm{m}$ and $\mathrm{u}^{*}=0.22 \mathrm{~m} / \mathrm{s}$. Measured longitudinal turbulence intensity $\mathrm{I}_{\mathrm{u}}$ ranges from $20 \%$ near ground-level to $2 \%$ at $\mathrm{z}=0.3 \mathrm{~m}$. Turbulent kinetic energy is determined using $\mathrm{k}=0.5\left(\sigma_{\mathrm{u}}{ }^{2}+\sigma_{\mathrm{v}}{ }^{2}+\sigma_{\mathrm{w}}{ }^{2}\right)$ and assuming $\sigma_{\mathrm{v}}=\sigma_{\mathrm{w}}=0.5 \sigma_{\mathrm{u}}$ where $\sigma_{\mathrm{u}}, \sigma_{\mathrm{v}}$ and $\sigma_{\mathrm{w}}$ denote the standard deviation of turbulent fluctuations in $\mathrm{x}, \mathrm{y}$ and $\mathrm{z}$ direction respectively. Turbulence dissipation rate $\varepsilon=\mathrm{u}^{* 3} / \mathrm{Kz}$. Because of the low exhaust momentum ratio and the resulting importance of accurate near-wall modelling in this case study, two types of near-wall modelling are employed: standard wall functions and the so-called "enhanced wall treatment". The latter option equals low-Reynolds number modelling provided that the near-wall grid resolution is sufficiently fine (e.g. $\mathrm{z}^{+}<5$ ). This option however does not allow specifying a roughness height $\mathrm{k}_{\mathrm{S}}$ in Fluent 6.1 and assumes a smooth ground surface. This will lead to streamwise gradients due to an incorrect roughness specification. The difference between the inlet profiles and the incident profiles is shown in Fig. 3b. The incident profiles are those in an equivalent empty computational domain, at the location where the building would be located. Fig. $3 \mathrm{~b}$ illustrates that in this case, the changes remain limited, mainly because of the very short upstream length (Blocken et al. 2007a). The top and sides of the domain are modelled as slip walls. Specifying fixed values at the top of the domain, as done in section 3.1, is less important here because only near-field dispersion is considered. At the outlet, zero static pressure is set. Li and Meroney (1983) studied gas dispersion from three different rooftop vents (Fig. 3a). In this study, only release from the middle vent is considered.

Simulations are made with combinations of the realizable k- $\varepsilon$ model, the RSM, standard wall functions and enhanced wall treatment. $\mathrm{z}^{+}$values on the roof are below 5 indicating that the grid resolution is appropriate for low-Re number modelling but too fine for the wall function approach. Note that Fluent 6.1 uses the Wolfstein model (Wolfstein 1969) for low-Re number modelling in combination with the k- $\varepsilon$ and RSM high-Re number models (two-layer zonal approach). Pressure-velocity coupling is done by the SIMPLE algorithm. Second-order discretisation schemes are used.

The experimental and the numerical results are presented as dimensionless concentration coefficients $\mathrm{K}=$ $\mathrm{CU}_{\mathrm{H}} \mathrm{L}^{2} / \mathrm{Q}_{\mathrm{e}}$, where $\mathrm{C}$ is the mass fraction of the tracer gas, $\mathrm{L}$ the size of the cube $(\mathrm{m})$ and $\mathrm{Q}_{\mathrm{e}}$ the emission rate of the pollutant $\left(\mathrm{m}^{3} / \mathrm{s}\right)$. Figs. $4 \mathrm{a}$ and $\mathrm{b}$ compare different numerical results with the experiments, along the rooftop 
centreline and along the leeward facade centreline. For all model combinations tested, the numerical discretisation error $\varepsilon_{\mathrm{d}}$ on the roof centreline is generally below $20 \%$, except near the leading edge, while $\varepsilon_{\mathrm{d}}$ on the facade centreline is generally below $5 \%$. The experiments indicate that the plume on the roof is dispersed in both the upstream and downstream direction from the vent (Fig. 4a), because the exhaust momentum $(\mathrm{M}=0.07)$ is too low to allow the plume to escape the recirculation bubble on the roof. As a result, the concentration coefficients on the leeward facade are very low (Fig. 4b). The CFD results obtained with $\mathrm{Sc}_{\mathrm{t}}=0.3$ in Fig. $4 \mathrm{a}$ show that low-Re number modelling provides significantly better upstream results than the wall function approach, with the RSM performing only slightly better than the realizable k- $\varepsilon$ model. The main conclusion, however, is that both the upwind and the downwind dispersion are significantly underestimated by all models. Fig. $4 \mathrm{c}$ and $\mathrm{d}$ indicate the effect of different $\mathrm{Sc}_{\mathrm{t}}$ numbers (RSM, enhanced wall treatment). Although a higher $\mathrm{Sc}_{\mathrm{t}}$ appears to provide a better prediction of the upwind dispersion, there are no noticeable differences for the downwind dispersion. From this result, it can not be concluded that $\mathrm{Sc}_{\mathrm{t}}=1.0$ is the best number to use, because other model deficiencies such as the numerical steady-state approximation of inherently transient flow might be more important and might lead to the wrong conclusion concerning the most appropriate $\mathrm{Sc}_{\mathrm{t}}$ number. The importance of transient flow features in pollutant dispersion was also suggested by Leitl et al. (1997) and Meroney et al. (1999). Note that Fig. 4c and d also hold the $\mathrm{K}$ values obtained with the semi-empirical minimum dilution Wilson-Lamb model (ASHRAE 1999) that provides minimum dilution ratios or maximum concentration coefficients. Finally, Fig. 5 displays contours of experimental and numerical (RSM, enhanced wall treatment, $\mathrm{Sc}_{\mathrm{t}}$ $=0.3) \mathrm{K}$ values on the roof. Apart from the underestimation of upwind and downwind dispersion, it clearly illustrates the large underestimation of lateral dispersion on the roof. These discrepancies are mainly attributed to inaccurate modelling of the size and the nature of the separation bubble (e.g. steady-state instead of transient). Note that a similarly large underestimation of the lateral dispersion was found for $\mathrm{Sc}_{\mathrm{t}}=0.2,0.3,0.5,0.7$ and 1.0.

\subsection{Dispersion around a low-rise rectangular building with rooftop structures}

In a previous study, Stathopoulos et al. (2004) performed field tests and wind tunnel experiments to investigate the dispersion of exhaust from rooftop stacks on a low-rise building $\left(\mathrm{H}_{\mathrm{b}}=12.6 \mathrm{~m}\right)$ in an urban environment. Fig. 6a illustrates the building together with the positions of the stacks SL1 to SL4. The tests focused on the influence of stack height, exhaust momentum ratio and upstream fetch on plume behaviour. In this paper, CFD simulations are performed in an attempt to reproduce one such experiment. For simplicity, a situation with the wind approaching over a relatively open fetch (Stathopoulos et al. 2004) is selected. The test under consideration was conducted with stack SL4, with a stack height of $1 \mathrm{~m}$, an inner diameter of $0.4 \mathrm{~m}$ and a momentum ratio $\mathrm{M}=10.7$. Wind direction was $150^{\circ}$ from north, which is nearly perpendicular to the windward facade. A simplified computational model is made, in which only the BE building itself is explicitly included, together with the three most prominent rooftop structures. Fig. $6 \mathrm{~b}$ illustrates the model and the computational grid on its surfaces. The domain has dimensions $\mathrm{LxBxH}=500 \times 500 \times 100 \mathrm{~m}^{3}$. The upstream length of the domain is only $50 \mathrm{~m}$, for reasons to be explained below. The grid resolution is selected based on the grid sensitivity analyses and grid choices from the previous two case studies in this paper. It consists of $1.02 \times 10^{6}$ prismatic cells. With the restriction $\mathrm{k}_{\mathrm{S}}<\mathrm{z}_{\mathrm{P}}$ in mind - as discussed in subsection 3.1 - the first grid layer at the bottom of the domain was taken deliberately large: $z_{\mathrm{P}}=2 \mathrm{~m}$ (see Fig. $6 \mathrm{~b}$ ). The inlet profile is a power law with exponent $\alpha$ $=0.30$ (Stathopoulos et al. 2004). The mean wind speed $U_{\text {ref }}$ at the location of the anemometer on top of a mast on the rooftop elevator structure is $1.6 \mathrm{~m} / \mathrm{s}$. Turbulent kinetic energy was determined from the turbulence intensity profile provided by Stathopoulos et al. (2004). Turbulence dissipation rate $\varepsilon=\mathrm{u}^{* 3} / \mathrm{Kz}$ with $\mathrm{u}^{*}=0.2 \mathrm{~m} / \mathrm{s}$. Especially for rough upstream terrain, problems with unintended streamwise gradients can occur. Therefore, two measures were taken: (1) the upstream terrain length in the domain was kept as short as possible (50 m) and (2) the height of the cell layer adjacent to the ground surface was taken quite large $\left(\mathrm{z}_{\mathrm{P}}=2 \mathrm{~m}\right)$. Nevertheless, $\mathrm{k}_{\mathrm{S}, \mathrm{ABL}}$ $=z_{p}=2 \mathrm{~m}$ is too low for urban terrain (Blocken et al. 2007a) and as a result streamwise gradients will occur, as demonstrated by a simulation in an empty computational domain (Fig. 7). Changes in the mean velocity profile are limited, but differences in the $\mathrm{k}$ profiles are considerable. The top of the domain is modelled as a slip wall, which is acceptable because of the very short upstream terrain length, and zero static pressure is set at the outlets.

Simulations are made with the RSM with enhanced wall treatment, although $\mathrm{z}^{+}$at several positions on the roof exceeds 5. Pressure-velocity coupling is taken care of by the SIMPLE algorithm and second-order discretisation schemes are used for both the convection and the viscous terms of the equations. $\mathrm{Sc}_{\mathrm{t}}=0.3$ is used.

Fig. 8 compares the experimental and the numerical dimensionless concentration coefficients $100 \mathrm{~K}=$ $100 \mathrm{CU}_{\mathrm{ref}} \mathrm{H}_{\mathrm{b}}{ }^{2} / \mathrm{Q}_{\mathrm{e}}$ where $\mathrm{H}_{\mathrm{b}}$ is the building height. Considering the large uncertainties and the very simplified modelling exercise, the agreement at several positions is remarkable. The numerical simulations however do not show the upwind dispersion and significantly overestimate the concentrations at the three receptors on the leeward facade. Similar to the two previous case studies, also these results show that lateral (cross-wind) 
dispersion can be significantly underestimated by CFD. This can partly be explained by the wind direction fluctuations that occurred during the $50 \mathrm{~min}$. field tests but is believed to be also caused by numerical model deficiencies.

\section{Further comments}

Steady-state RANS CFD simulations of pollutant dispersion have been conducted for three case studies of increasing complexity. The main observation from all three cases is that the numerical simulations significantly underestimate the cross-wind (lateral) dispersion of the pollutants. This can, at least to some extent, be attributed to the steady-state modelling of essentially transient flow features and the occurrence of unintended streamwise gradients in the vertical profiles of turbulent kinetic energy. For every case study separately, the following specific observations are made:

- For dispersion from isolated stacks under neutral open country conditions, the standard k- $\varepsilon$ model in combination with standard wall functions and $\mathrm{Sc}_{\mathrm{t}}=0.3$ can provide acceptable predictions of concentrations in a vertical centre plane through the stack that is parallel with the wind direction. In this plane, apart from near-field ground-level concentrations for the $16 \mathrm{~m}$ stack, the numerical predictions are within a factor of 3 from the Gaussian model results. The overestimations in the vertical centre plane are directly related to the underestimation of cross-wind (lateral) dispersion. The results are quite sensitive to the value of the turbulent Schmidt number.

- The low-momentum pollutant exhaust from the flush vent on the cubic building roof is trapped inside the separation bubble. Upwind, downwind and especially cross-wind dispersion are all significantly underestimated, even if the Reynolds Stress model with the low-Re Wolfstein model is applied. This can - at least partly - be attributed to the transient character of separated flow on the roof, in which the separation bubble intermittently forms and disappears. Only upwind dispersion appears to be significantly influenced by the value of the turbulent Schmidt number.

- The third case combines the former two cases by focusing on stack emission that is partly trapped into recirculation regions on the roof around the rooftop structures. It is expected that several numerical modelling errors and modelling uncertainties are balancing each other out, yielding an overall fair agreement between measurements and numerical simulations.

Further research should be directed towards identifying the main reasons for numerical modelling discrepancies based on idealized case studies, such as dispersion from isolated stacks and from isolated building vents, to support future applications for more complex case studies.

\section{Conclusions}

- The dispersion of plumes from the isolated stacks could generally be predicted within a factor of 3 in the vertical stack centre plane that is parallel with the wind direction. Lateral dispersion however was severely underestimated.

- Upwind dispersion of low-momentum exhaust from a rooftop vent in the roof recirculation bubble could to some extent be simulated, but downwind and lateral dispersion were severely underestimated.

- Simulations of dispersion on the rectangular building with rooftop structures provided fairly good predictions at some locations, but significantly underestimated upwind and lateral dispersion.

- All simulations were conducted with the steady-state RANS approach, which is considered to be at least partly responsible for the lack of lateral dispersion.

- In two out of three simulations, the vertical turbulent kinetic energy profiles showed significant unintended streamwise gradients in the computational domain, which are also considered an important source of error.

\section{References}

ASHRAE, 1999. Building air intake and exhaust design. ASHRAE Application Handbook, Atlanta, Chapter 43.

ASHRAE, 2003. Building air intake and exhaust design. ASHRAE Application Handbook, Atlanta, Chapter 44.

Banks, D., Meroney, R. N., Petersen, R. L., Carter, J. J., 2003. Evaluation of FLUENT for predicting concentrations on buildings, A\&WMA Conference, San Diego, CA, Paper \# 70223.

Barad, M.L., 1958. Project Prairie Grass. A field program in diffusion. Geophysical Research Paper, No. 59, Vols. I and II, Report AFCRC-TR-58-235, Air Force Cambridge Research Center, Bedford, MA.

Blocken, B., Stathopoulos, T., Carmeliet, J. 2007a. CFD simulation of the Atmospheric Boundary Layer - wall function problems. Atmospheric Environment 41, 2, 238-252. 
Blocken, B., Carmeliet, J., Stathopoulos, T., 2007b. CFD evaluation of the wind speed conditions in passages between buildings - effect of wall-function roughness modifications on the atmospheric boundary layer flow, Journal of Wind Engineering and Industrial Aerodynamics 95, 9-11, 941-962.

Briggs, G.A., 1984. Plume rise and buoyancy effects. Atmospheric Science and Power Production. RAnders, Ed. U.S. Department of Energy D.O.E./TIC-27601 (DE 84005177), Washington, D.C.

Cebeci, T., Bradshaw, P., 1977. Momentum transfer in boundary layers. Hemisphere Publishing Corporation, New York.

Fluent Inc., 2003. Fluent 6.1 User's Guide, Fluent Inc., Lebanon.

Franke, J., Hellsten, A., Schlünzen, H., Carissimo, B., 2007. Best practice guideline for the CFD simulation of flows in the urban environment. COST Action 732: Quality Assurance and Improvement of Microscale Meteorological Models.

Gibson, M.M., Launder, B.E., 1978. Ground effects on pressure fluctuations in the Atmospheric Boundary Layer. Journal of Fluid Mechanics 86, 491-511.

Halitsky, J., 1963. Gas diffusion near buildings. ASHRAE Transactions 69, 464-485.

Huber A.H., Snyder, W.H., 1982. Wind tunnel investigation of the effects of a rectangular shaped building on dispersion of effluent from short adjacent stacks. Atmospheric Environment 16, 12, 2837-2848.

Jones, W.P., Launder, B.E., 1972. The prediction of laminarization with a 2-equation model of turbulence. International Journal of Heat and Mass Transfer 15, 301.

Launder, B.E., 1989. Second-moment closure and its use in modeling turbulent industrial flows. International Journal for Numerical Methods in Fluids 9, 963-985.

Launder, B.E., Reece, G.J., Rodi, W., 1975. Progress in the development of a Reynolds-stress turbulence closure. Journal of Fluid Mechanics 68, 3, 537-566.

Launder, B.E., Reece, G.J., Rodi, W., 1975. Progress in the development of a Reynolds-stress turbulence closure. Journal of Fluid Mechanics 86, 537-566.

Launder, B.E., Shima, N. 1989. Second-moment closure for the near-wall sublayer: development and application. AIAA Journal 27, 10, 1319-1325.

Launder, B.E., Spalding, D.B., 1974. The numerical computation of turbulent flows, Computer Methods in Applied Mechanics and Engineering 3, pp. 269-289.

Lazure, L., Saathoff, P., Stathopoulos, T., 2002. Air intake contamination by building exhausts: tracer gas investigation of atmospheric dispersion models in the urban environment. Journal of the Air \& Waste Management Association 52, 160166.

Leitl, B.M., Kastner-Klein, P., Rau, M., Meroney, R.N., 1997. Concentration and flow distributions in the vicinity of Ushaped buildings: Wind-tunnel and computational data. Journal of Wind Engineering and Industrial Aerodynamics 67\&68: 745-755

Li, W., Meroney, R.M., 1983. Gas dispersion near a cubical model building - Part I. Mean concentration measurements. Journal of Wind Engineering and Industrial Aerodynamics 12, 15-33.

Li, Y., Stathopoulos, T., 1997. Numerical evaluation of wind-induced dispersion of pollutants around a building. Journal of Wind Engineering and Industrial Aerodynamics 67\&68, 757-766.

Li, Y., Stathopoulos, T., 1998. Computational evaluation of pollutant dispersion around buildings: Estimation of numerical errors. Journal of Wind Engineering and Industrial Aerodynamics 77\&78, 619-630.

Meroney, R.N., Leitl, B.M., Rafailidis, S., Schatzmann, M., 1999. Wind tunnel and numerical modelling of flow and dispersion about several building shapes. Journal of Wind Engineering and Industrial Aerodynamics 81, 1-3, 333-345.

Meroney, R.N., 2004. Wind tunnel and numerical simulation of pollution dispersion: a hybrid approach. Working paper, Croucher Advanced Study Insitute on Wind Tunnel Modeling, Hong Kong University of Science and Technology, 6-10 December, 2004, 60 pp.

Pasquill, F., Smith, F.B., 1983. Atmospheric diffusion. $3^{\text {rd }}$ Edition, Ellis Horwood Ltd., Chichester, England.

Riddle, A., Carruthers, D., Sharpe, A., McHugh, C., Stocker, J., 2004. Comparisons between FLUENT and ADMS for atmospheric dispersion modeling. Atmospheric Environment 38, 1029-1038.

Saathoff, P., Stathopoulos, T., Wu, H., 1998. The influence of freestream turbulence on nearfield dilution of exhaust from building vents. Journal of Wind Engineering and Industrial Aerodynamics 77\&78, 741-752.

Saathoff, P.J., Stathopoulos, T., Dobrescu, M., 1995. Effects of model scale in estimating pollutant dispersion near buildings. Journal of Wind Engineering and Industrial Aerodynamics 54\&55, 549-559.

Shih, T.H., Liou, W.W., Shabbir, A., Zhu, J., 1995. A new k- $\varepsilon$ eddy-viscosity model for high Reynolds number turbulent flows - model development and validation. Computers and Fluids 24, 3, 227-238.

Stathopoulos, T., Storms, R., 1986. Wind environmental conditions in passages between buildings. Journal of Wind Engineering and Industrial Aerodynamics 24, 19-31.

Stathopoulos, T., Lazure, L., Saathoff, P., Wei, X., 2002. Dilution of exhaust from a rooftop stack on a cubical building in an urban environment. Atmospheric Environment 36, 4577-4591.

Stathopoulos, T., Lazure, L., Saathoff, P., Gupta, A., 2004. The effect of stack height, stack location and rooftop structures on air intake contamination: A laboratory and full-scale study, Report R-392, IRSST, Quebec, 2004.

Tang, W., Huber, A., Bell, B., Kuehlert, K., Schwarz, W., 2005. Example application of CFD simulations for short-range atmospheric dispersion over the open fields of Project Prairie Grass, A\&WMA Conference, 2005, Paper \# 1243.

Turner, D.B., 1970. Workbook of atmospheric dispersion estimates. Environmental Protection Agency, Environmental Health Series, Air Pollution, 84pp. 
Wang, X. 2006. Numerical simulation of wind-induced dispersion of emissions from rooftop stacks. M.A.Sc Thesis, Department of Building, Civil and Environmental Engineering, Concordia University, Montreal, Canada.

Wang, X., Stathopoulos, T., Saathoff, P., 2006. Numerical evaluation of dispersion of pollutants in the building environment: comparisons with models and experiments. $6^{\text {th }}$ International Conference on Computational Wind Engineering, Yokohama, Japan.

Wilson, D.J., Lamb, B., 1994. Dispersion of exhaust gases from roof level stacks and vents on a laboratory building. Atmospheric Environment 28, 19, 3099-3111.

Wolfstein, M., 1969. The velocity and temperature distribution of one-dimensional flow with turbulence augmentation and pressure gradient. International Journal of Heat and Mass Transfer, 12, 301-318.

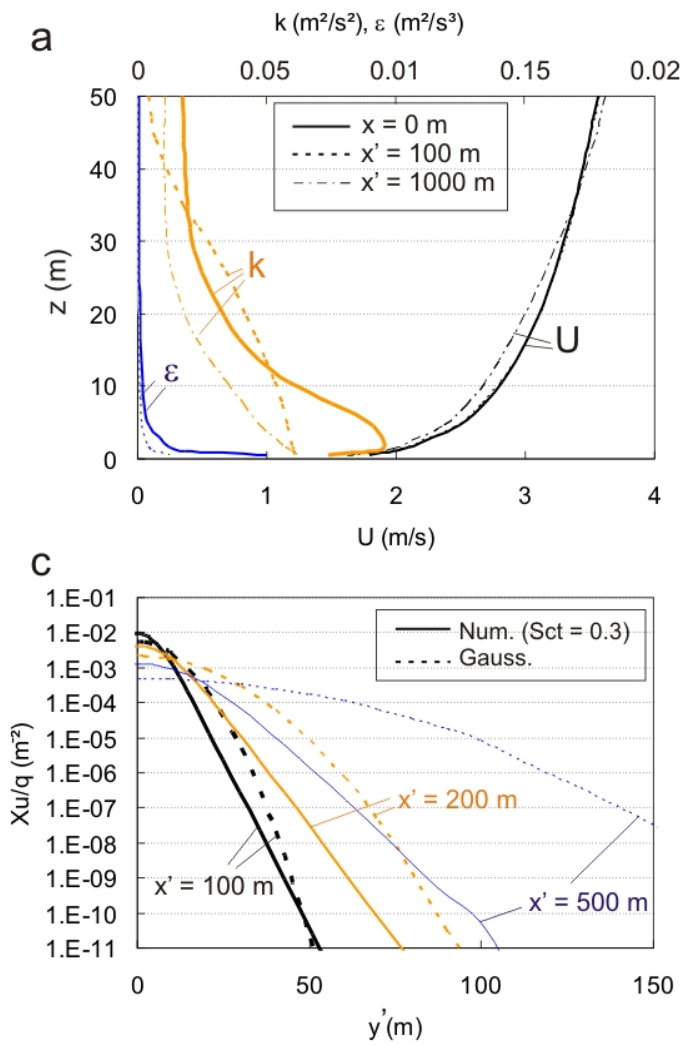

b

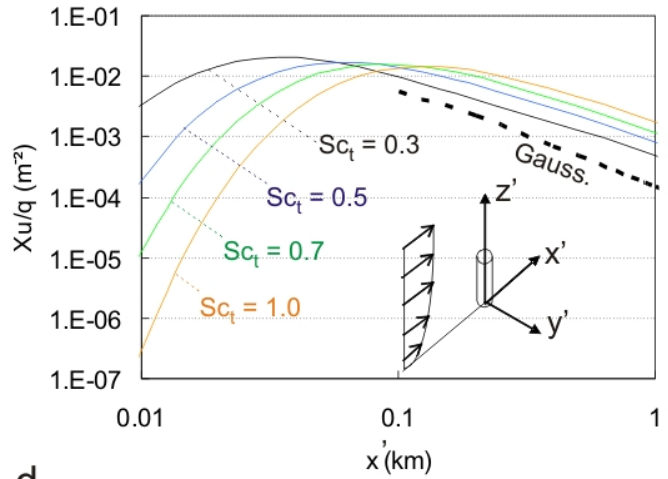

d

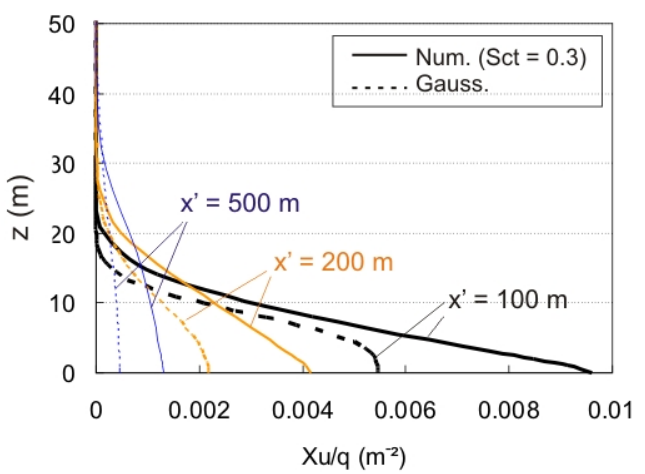

Figure 1. Stack of $2 \mathrm{~m}$ height, $\mathrm{M}=4$. (a) Vertical profiles of $\mathrm{U}, \mathrm{k}$ and $\varepsilon$ at different downstream positions in the domain (stack location $\mathrm{x}=14 \mathrm{~m}$ ). (b) Ground-level downstream concentration profiles: numerical results for different Schmidt numbers and Gaussian model prediction. (c) Ground-level lateral concentration profiles: CFD $\left(\mathrm{Sc}_{\mathrm{t}}=0.3\right)$ versus Gaussian model. (d) Vertical concentration profiles: $\mathrm{CFD}\left(\mathrm{Sc}_{\mathrm{t}}=0.3\right)$ versus Gaussian model. 

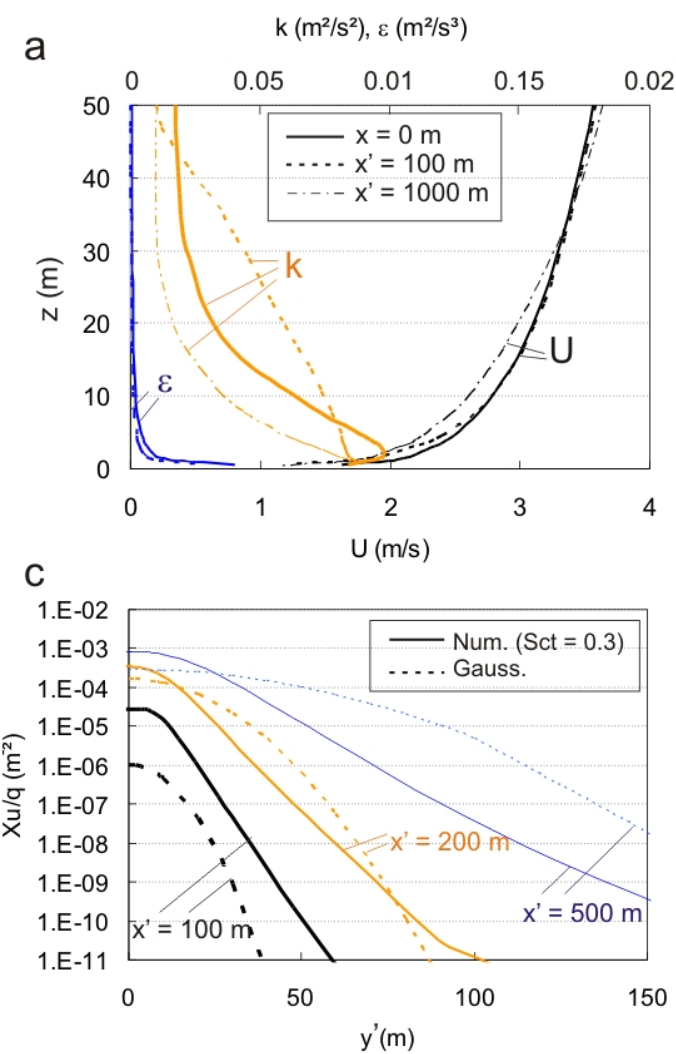

b

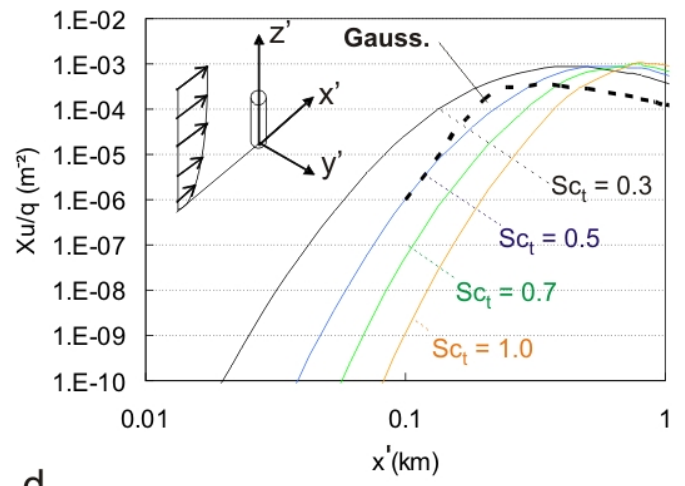

d

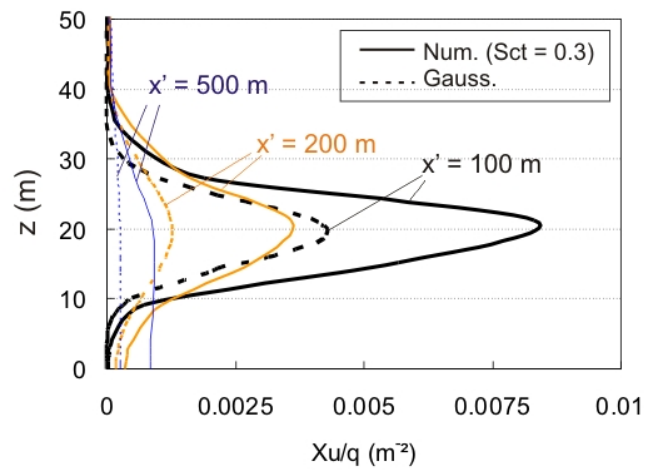

Figure 2. Stack of $16 \mathrm{~m}$ height, $\mathrm{M}=2$. (a) Vertical profiles of $\mathrm{U}, \mathrm{k}$ and $\varepsilon$ at different downstream position in the domain (stack location $\mathrm{x}=42 \mathrm{~m}$ ). (b) Ground-level downstream concentration profiles: numerical results for different Schmidt numbers and Gaussian model prediction. (c) Ground-level lateral concentration profiles: CFD $\left(\mathrm{Sc}_{\mathrm{t}}=0.3\right)$ versus Gaussian model. (d) Vertical concentration profiles: $\mathrm{CFD}\left(\mathrm{Sc}_{\mathrm{t}}=0.3\right)$ versus Gaussian model.

a

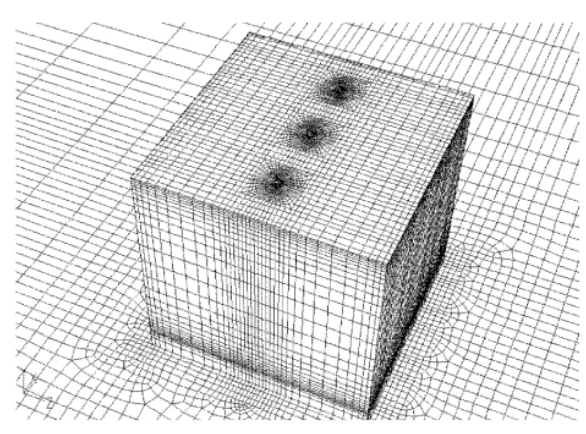

b

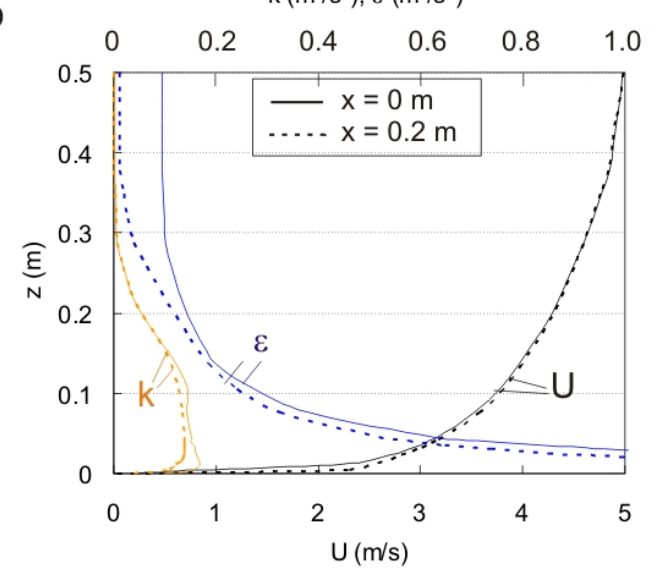

Figure 3. (a) Grid on cube and ground surface. (b) Inlet and incident vertical flow profiles. 


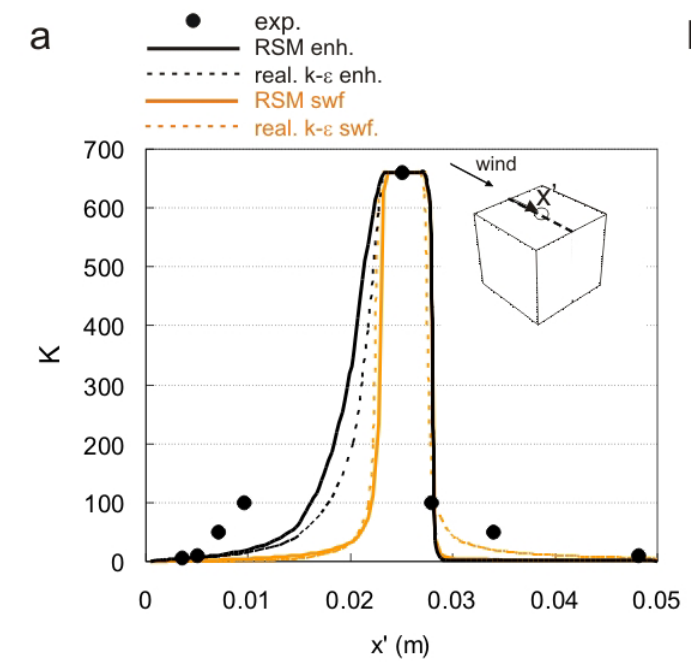

b
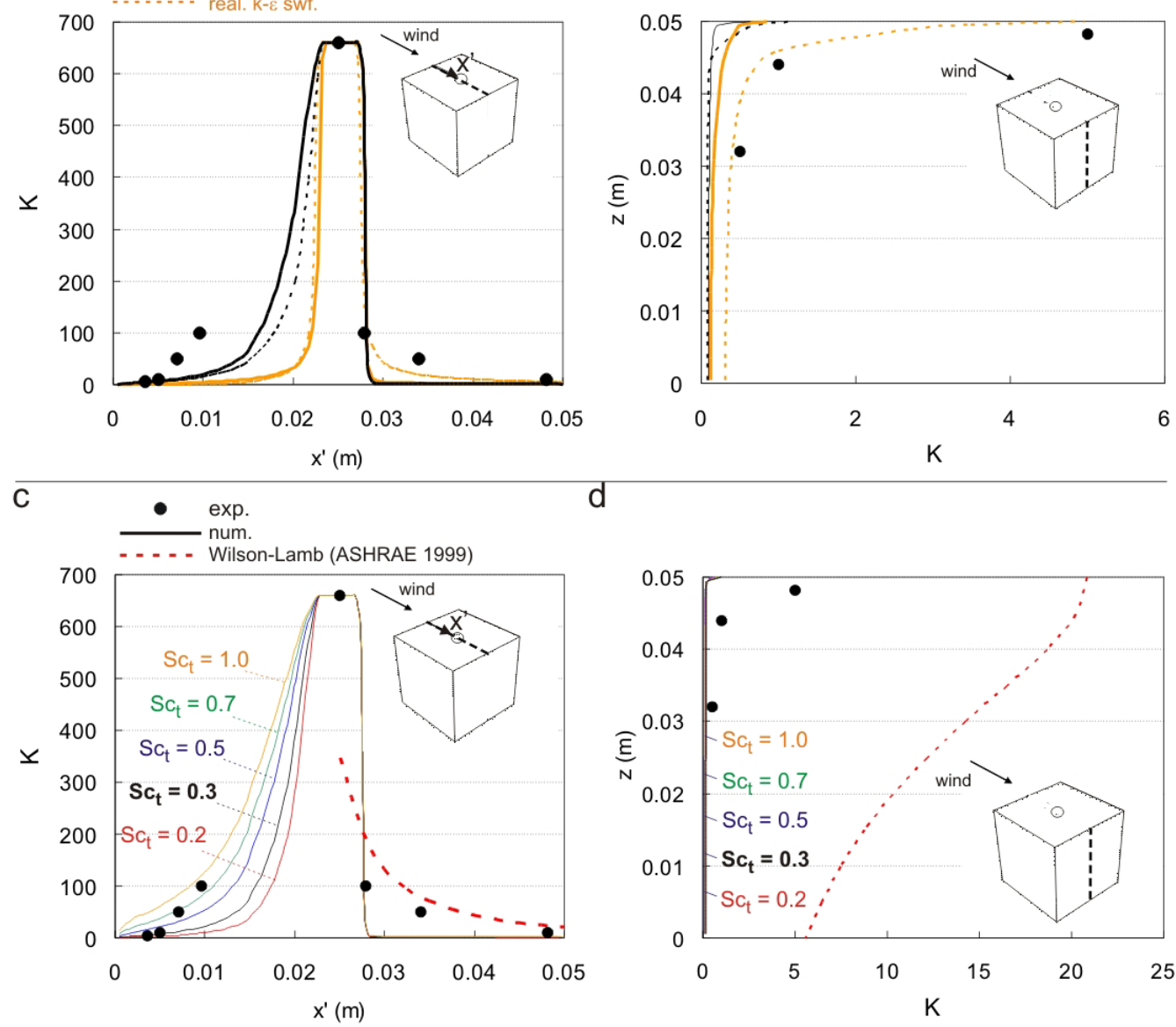

d

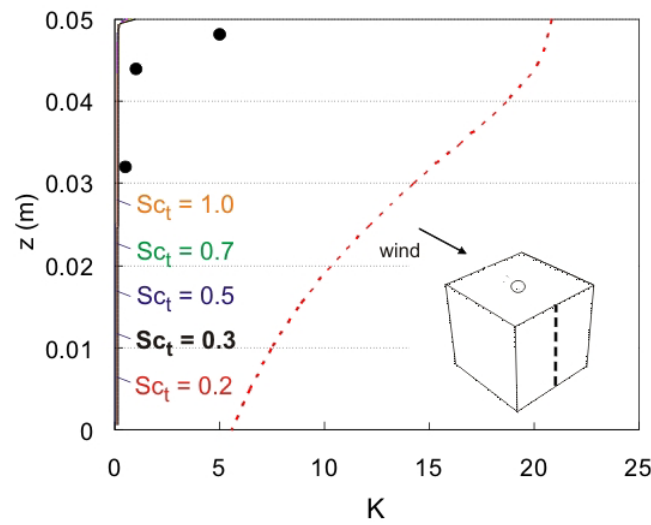

Figure 4. (a-b) Numerical results with different turbulence models and near-wall treatments $\left(\mathrm{Sc}_{\mathrm{t}}=0.3\right)$ versus experiments, both in terms of dimensionless concentration coefficient $\mathrm{K}$. (a) along roof centreline; (b) along leeward facade centreline. (c-d) Numerical results (RSM, enhanced wall treatment) with different $\mathrm{Sc}_{\mathrm{t}}$ versus experiments and Wilson-Lamb minimum dilution model. (c) along roof centreline; (d) along leeward facade centreline.

a
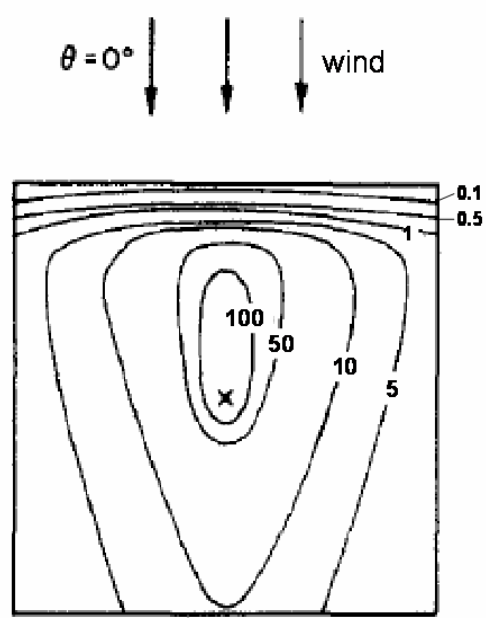

b
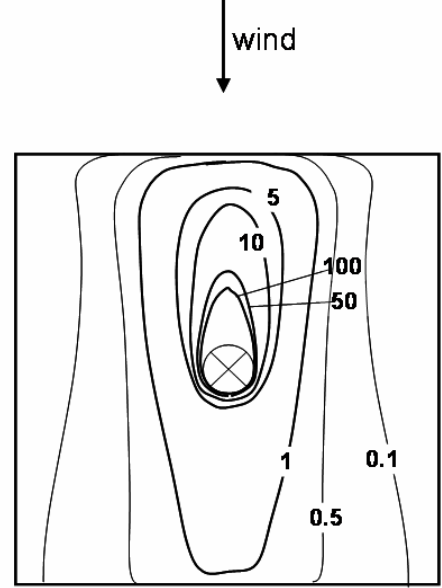

Figure 5. (a) Experimental versus (b) numerical results (RSM, enhanced wall treatment, $\mathrm{Sc}_{\mathrm{t}}=0.3$ ) of the dimensionless concentration coefficient $\mathrm{K}$ on the roof. 
a

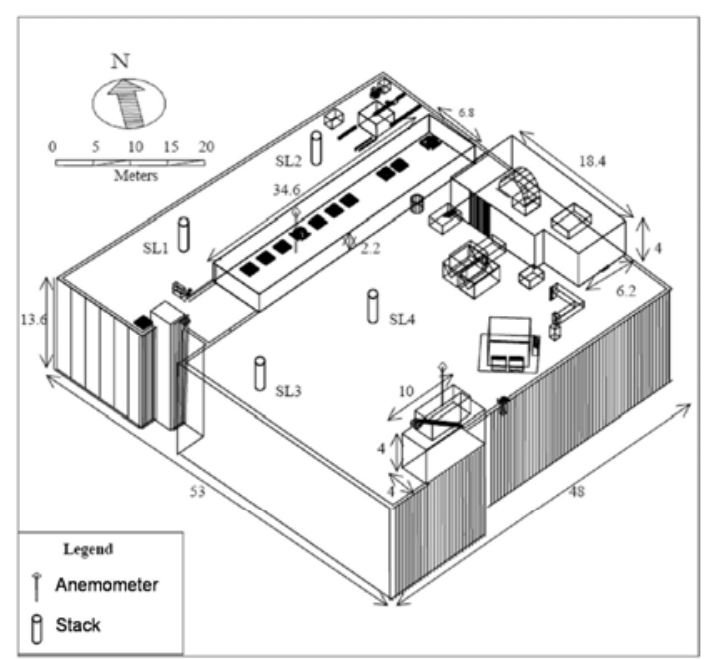

b

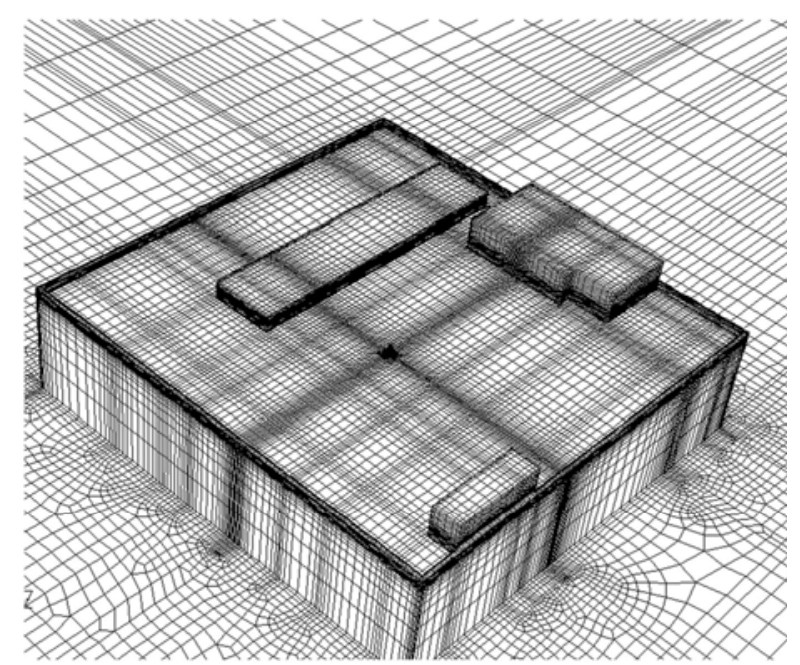

Figure 6. (a) Geometry of the BE building and dimensions in meter. (b) Mesh on the building and ground surface.

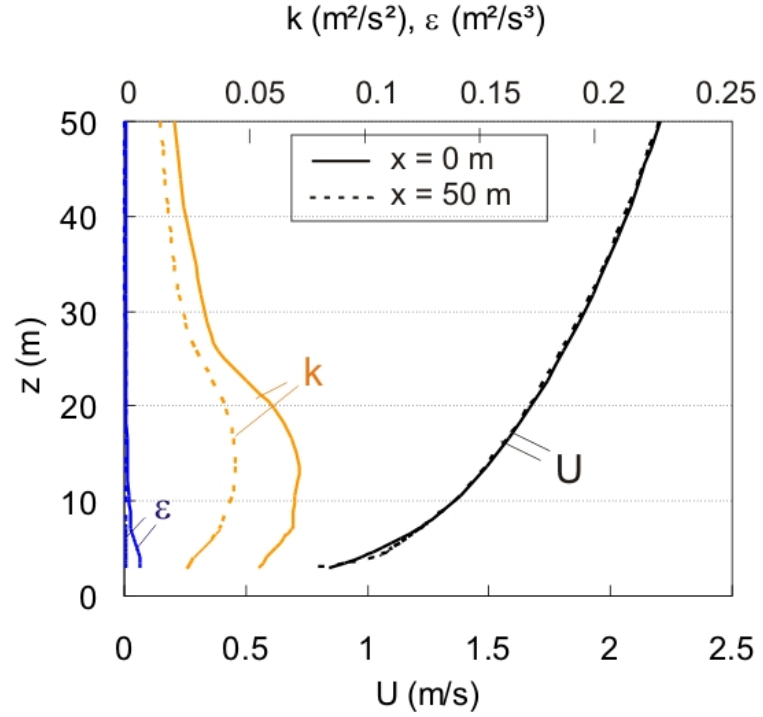

Figure 7. Inlet versus incident vertical flow profiles $(\mathrm{x}=0 \mathrm{~m}$ is inlet of domain, $\mathrm{x}=50 \mathrm{~m}$ is building position). 
a

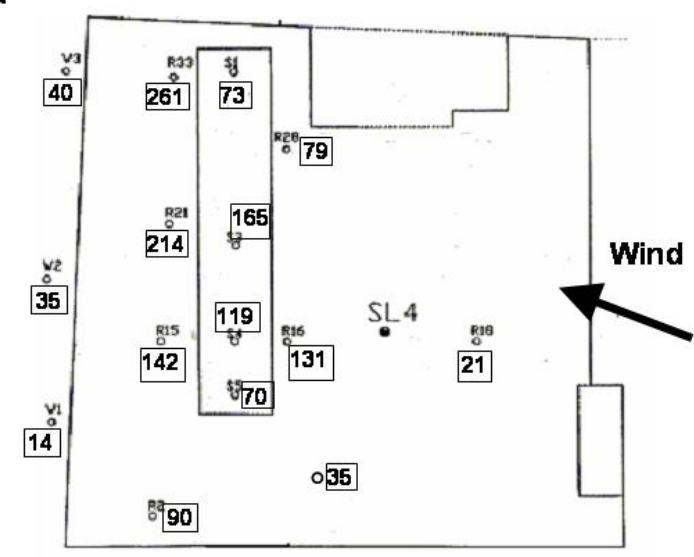

FIELD TESTS b

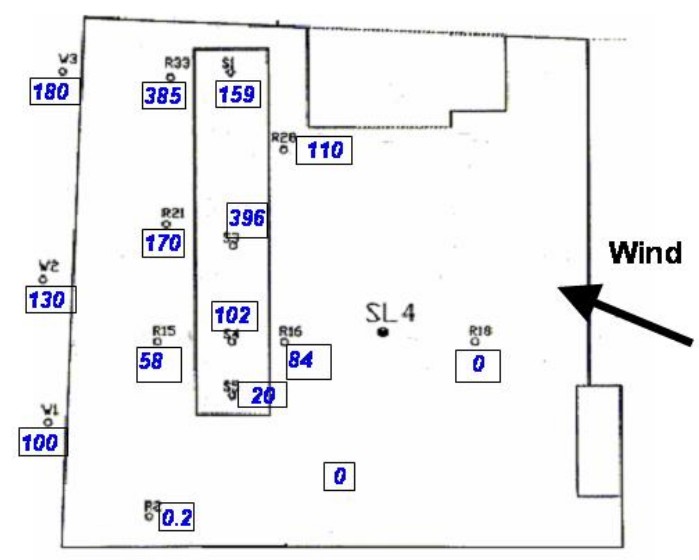

NUMERICAL RESULTS

Figure 8. (a) Full-scale experimental versus (b) numerical results (RSM, enhanced wall treatment, $\mathrm{Sc}_{\mathrm{t}}=0.3$ ) of dimensionless concentration coefficient $(100 \mathrm{~K})$ at receptors on roof and facade. 